\title{
The Feasibility of Utilizing Wind Energy in Commercial Buildings With Special Reference to the Kingdom of Bahrain
}

\author{
Saeed Abdulrahim Saeed* \\ Department of Architecture and Interior Design \\ College of Engineering, University of Bahrain \\ sabdulrahim@uob.edu.bh; saeedibnouf@gmail.com
}

\begin{abstract}
This article shall investigate the feasibility of utilizing wind energy for commercial buildings with special reference to the Kingdom of Bahrain. Bahrain World Trade Center which was built in 2008, is located in the city of Manama. The fifty-story complex contains identical twin towers that rise over 240 meters in height. The towers are connected by three bridges which hold three turbines each 29 meters long. The three turbines were originally design to provide electric energy required for lighting. The Bahrain World Trade Center was selected as a case study to investigate the feasibility of utilizing wind energy technologies in skyscrapers with special reference to the Kingdom of Bahrain. It is hoped that the findings and conclusion of the study shall be of some value for future utilization of wind energy in the GCC countries and the world at large.
\end{abstract}

Keywords: wind energy, renewable energy in buildings, wind turbines and skyscrapers

\section{Introduction}

Buildings in the Gulf Countries; Kingdom of Saudi Arabia, United Arab Emirate, Kuwait, Oman and the Kingdom of Bahrain are consuming the largest proportion of the generated fossil energy production. In fact the electric energy consumption is increasing at a very high rate due to the increase in population and the vast expansion of urban settlements. Bahrain produces $2800 \mathrm{MW}$ of electricity and 140 million gallons per day of desalinated water using fossil fuel as the main energy source. In 2009, a consultation committee was established with a view to establishing a solar and wind hybrid pilot project with a capacity of between 3 and 5 MW. Bahrain ratified the Kyoto Protocol in May 2006. However, the country remains heavily dependent on the oil sector. Petroleum revenues make up about two-thirds of government revenue and export earnings. Hydrocarbons also provide the foundation for Bahrain's two major industries; refining and aluminum smelter. In addition, in Bahrain as with other countries across the GCC, electricity production is heavily subsidized and supplied at a price which is far less than the cost of generation ${ }^{1}$. Cheap electric energy cost may not encourage people to reduce their energy consumption. Recently the Water and Electricity Authority in the Kingdom of Bahrain, is in the process to increase the cost of both water and 
electricity, this might help in decreasing electricity and water consumption. Approximately, $60 \%$ of the generated electric energy in Bahrain is consumed in buildings, and the remaining percentage is consumed by all other sectors, i.e. industry, transportation, communication, agriculture etc. Furthermore, buildings emits $30 \%$ of carbon dioxide and $25 \%$ of nitrogen oxide found in the air ${ }^{2}$. Currently the vast majority of this energy is produced from non-renewable fossil fuel sources, i.e. oil and gas. With uncertainty over the availability of oil and gas productions into the future, rising demands for fossil energy and increasing the emission of $\mathrm{CO} 2$ which is causing considerable climatic changes. Due to the global warming, there is a vital need for reducing the emission of $\mathrm{CO} 2$. The proposed strategy could summarized in the Figure 1.
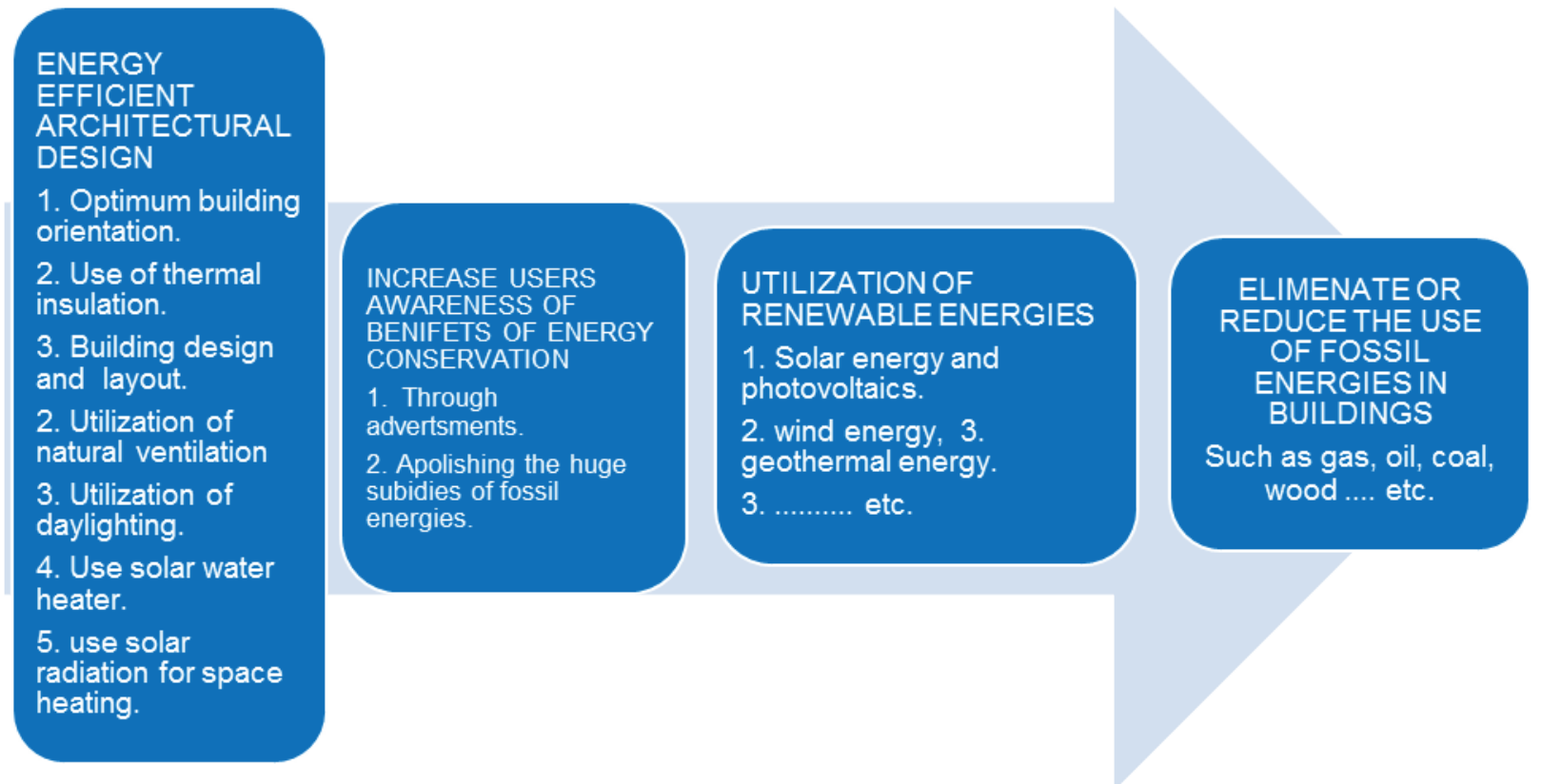

Figure 1. Energy Conservation Strategies.

\section{a). Energy Efficient Architectural Design:}

Architects and designers should adopt energy efficient architectural design strategies with the objective of utilizing the natural means to reduce energy needs. Energy conservation measures, and passive solar architectural design techniques which should be implemented, include; optimum building orientation in relation to sun movement and prevailing wind direction, adequate thermal insulation, use of reflected glass for openings, sun protection and proper shading devices ... etc. When energy efficient architectural design or the so called passive solar energy fails to provide optimum thermal comfort requirement renewable energy technologies could be adopted. Renewable energy is generally defined as energy 
that is collected from sources which are naturally replenished on a human time scale, such as sunlight, wind, rain, tides, waves and geothermal heat. Renewable energy often provides energy in four important areas: electricity generation, air and water heating and cooling, transportation and rural energy services. Based on REN21's 2016 report, renewable energies contributed $19.2 \%$ and $23.7 \%$ to humans' global energy consumption and the generation of electricity in 2014 and 2015 , respectively. This energy consumption is divided as $8.9 \%$ coming from traditional biomass, $4.2 \%$ as heat energy (modern biomass, geothermal and solar heat), $3.9 \%$ hydro-electricity and $2.2 \%$ is electricity from wind, solar, geothermal, and biomass. REN21's also indicated that worldwide investments in renewable technologies amounted to more than US\$286 billion in 2015, with countries like China and the United States heavily investing in wind, hydro, solar and biofuels. According to the International Energy Agency 2011, solar energy, radiant light and heat from the sun, is harnessed using a range of ever-evolving technologies such as solar heating, photovoltaic's, concentrated solar power (CSP), concentrator photovoltaic's (CPV), solar architecture and artificial photosynthesis ${ }^{3}$.

The main renewable energy technologies which are being widely used in buildings, are photovoltaic's (active solar energy) and wind energy. Solar cells when properly located on roofs and walls may provide a good proportion of electric energy which could be used for different indoor activities. The solar radiation falling on the solar cells shall be converted to a D.C. electric current which could be transformed to A.C electric current ready to be used by any electrical appliances. The production of electricity by photovoltaic's is getting a considerable attention by scientists and engineers, and a lot of developments is in progress with the objective of increasing the efficiency of electric energy production and reducing the capital and running cost.

\section{b). Wind Energy:}

Wind moves horizontally due to difference in pressure, from high pressure zone to a lower pressure zone, and moves vertically due to difference in temperature. In fact wind exists because the sun unevenly heats the surface of the earth. The temperature of air molecules which are in touch of the heated surface of the earth will increase, their density will decrease and become lighter and will move upward being replaced by cooler molecules. This air movement will continue as long as the sun shines. Wind power is the conversion of wind energy into alternate forms of energy, including wind turbines for the production of electrical wind power, windmills for mechanical power, and wind pumps for water pumping or drainage. Wind energy was used by mariners to move boats and ships, and by farmers to grind their grains and pump water. Recently more people are using wind turbines to generate electricity. Wind is a clean energy that 
produces no air or water pollution. Since the wind is free, operational costs are nearly zero once a turbine is erected. Mass production and technology advances are making turbines cheaper, which will spread the utilization of wind energy in buildings ${ }^{1}$.

The term wind energy or wind power describes the process by which the wind is used to generate mechanical power or electricity. Wind turbine convert the kinetic energy into mechanical power. A wind turbine is a machine that transforms the kinetic energy of the wind into mechanical or electrical energy. Generally, wind turbines consist of a foundation, a tower, a nacelle and a rotor. The foundation is for supporting the turbine, while the tower holds up the rotor and a nacelle (or box). The nacelle contains large primary components such as the main axle, gearbox, generator, transformer and control system. The rotor is made of 2 or 3 blades and the hub which holds them in position as they turn ${ }^{1}$. Wind turbines could be basically classified into two groups; horizontal-axis turbines and vertical axis turbines. Mathias Aarre Maehlum ${ }^{4}$, listed the most important facts about the wind power that should be included on any balanced wind energy, these are as horizontal and vertical wind turbines ${ }^{4}$. Horizontal Axis Wind Turbines require a "yaw" mechanism to turn the turbine against the wind direction in order to harvest the wind energy. They are usually installed high up above ground level on a tower in order to harvest the ample wind energy up in the sky. There are 2 types of blades that are used on these turbines ${ }^{4}$. The turbines are usually installed on or close to the ground level. However, the wind speed is always lower than that in the upper sky. There are also 2 types of blades that are used on these turbines ${ }^{5}$.

Horizontal Axis Wind Turbines require a "yaw" mechanism to turn the turbine against the wind direction in order to harvest the wind energy. They are usually installed high up above ground level on a tower in order to harvest the ample wind energy up in the sky. There are 2 types of blades that are used on these turbines ${ }^{4}$.

While the Vertical Axis Wind Turbines do not require a "yaw" mechanism to harvest the wind

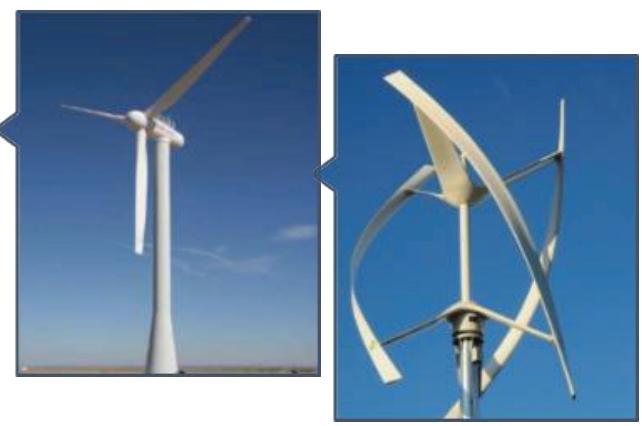

HAWT VAWT energy. Since the blades rotate 360 degree on the vertical shaft of the wind turbines, wind of any direction can turn the turbine.

The continuous development and technological advancement in the wind technology resulted in a wide variation in the design of wind turbines. This 
variations in the design of wind turbines reflects ongoing commercial, technological, and inventive interests in harvesting wind for the generation of energy. A quantitative measure of the wind energy available at any location is called the Wind Power Density (WPD). It is a calculation of the mean annual power available per square meter of swept area of a turbine., and is tabulated for different heights above ground. Calculation of wind power density includes the effect of wind velocity and air density ${ }^{6}$.

Advantages and disadvantages of wind energy technology could be summarized as follows ${ }^{4}$;

i). ). Advantages:

- Wind energy is a green energy source. Harnessing wind energy does not pollute the environment nearly as much as fossil, coal and nuclear power do.

- The potential of wind power is absolutely incredible. Harnessing wind energy can be done almost anywhere.

- Wind energy is a renewable source of energy. Wind is naturally occurring and there is no way we can empty the energy resources.

- i). Advantages:

- Wind energy is a green energy source. Harnessing wind energy does not pollute the environment nearly as much as fossil, coal and nuclear power do.

- The potential of wind power is absolutely incredible. Harnessing wind energy can be done almost anywhere.

ii). Disadvantages:

- Wind is unpredictable and the availability of wind energy is not constant. Wind energy is therefore not well suited as a base load energy source if we had a cost-effective ways of storing wind energy the situation would be different.

- We can hope for breakthroughs in energy storage technologies in future, but right no turbines have to be used in tandem with other energy sources.

- Birds, bats and other flying creatures have slim chances to of surviving when taking a direct hit from a rotating wind turbine.

- Noise is a problem for some people that live in the proximity of wind turbines building wind turbines in urban environments should be avoided Alex Wilson ${ }^{7}$, advocated that, building-integrated wind often doesn't live up to its promise. The turbines must overcome several challenges to meet performance expectations and be cost effective. Noise and vibration from wind turbines are among the greatest obstacles to integrating them into buildings. Based on the recent surge in building-integrated wind, one might think that engineers 
had beaten this problem. In truth, some wind turbines are a lot quieter than othersvertical-axis machines among them, but managing noise and vibration remains a huge challenge. Wind speed typically increases with height, as it is less affected by trees and surrounding topography. Putting wind turbines on top of buildingsespecially tall buildings - should allow them to take advantage of height without an expensive, full-size tower. In some cases, building geometry can enhance wind turbine performance. Several manufacturers of building-integrated wind turbines are taking advantage of the increased wind velocities at building parapets - where the wind rises up the façade of a large building and curls over the edge. Some architects are designing wind scoops right into the structures of buildings or situating building towers to funnel wind into turbines. Most of our electricity is used in buildings, and generating the electricity on site reduces the need for transmission. This in turn reduces transmission losses as well as the materials needed for wiring and poles. In addition to this practical benefit, wind turbines spinning on a building provide a visible testament to a building owner's commitment to the environment ${ }^{8}$.

In the wind turbines, the wind passes over the blades creating mechanical movement, which causes the rotor to turn. The blades turn a low-speed shaft inside the nacelle gears connect the low speed shaft of the rotor with a high speed shaft that drives a generator. Some of wind turbines do not contain gearbox and instead use a direct drive mechanism to produce power the generator. The rapidly spinning shaft drives the generator to produce electric energy. Electricity from the generator goes to a transformer which converts it to the right voltage for electricity grid. The electricity is then transmitted via the electricity network. The optimum number of blades for a wind turbine depends on the job the turbine has to do. Turbines for generating electricity need to be operate at high speeds, but do not need turning force. These machines generally have three or two blades. Two bladed machines are cheaper and lighter, with higher running speeds which reduces the costs of the gearbox, and they are easier to install. Their performance is somewhat similar to the three blades turbines, but according to experts, they produce more noise when compared with the three blades turbines, and they are not visually attractive when they are running ${ }^{8}$. Wind energy technologies can be used as stand-alone applications, connected to a utility grid, or even combined with photovoltaic system. Single small turbines, below 100 kilowatts, are used for homes, telecommunications dishes, or water pumping. Small turbines are sometimes used in connection with diesel generators, batteries, and photovoltaic systems. These systems are called hybrid wind systems and are typically used in remote areas where the connection to the grid is not available. Turbines sometimes have to be stopped for maintenance for repairing components or if there is a failure that needs to be checked. Also if the wind is too little or too much 
the turbines should be stopped, and high wind velocity might damage the turbine. Big environmental and nature conservation groups like Birdlife, Green Peace, Friends of the earth ... etc, support wind energy. Birdlife recently stated that climate change was the single largest threat to birds, and wind and renewable energy strategies were a clear solution to climate change. Wind energy emits no toxic substance such as mercury and air pollutants like smog-creating nitrogen oxides, acid rain-forming sulfur dioxide and particulate deposits which can cause serious respiratory diseases ${ }^{8}$. There are three options locating wind turbines on top of buildings, the first option is installing the wind turbines on top of the building as an independent object to utilize the high wind speed. The second option is the integration of wind turbine in the construction of buildings, where the building itself mount the turbine. The third option is the installation of wind turbines between two towers and well integrated with the structure of the two towers, such as Bahrain World Trade Center.

\section{c). Bahrain World Trade Center (BWTC).}

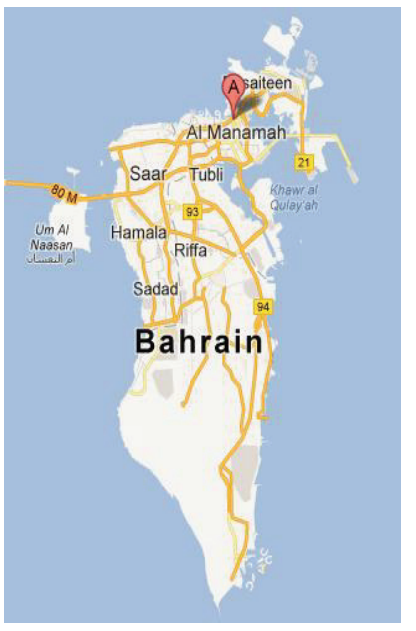

Right:

World trade Center,
Sheraton Hotel,
Diplomatic area

Map of Bahrain showing the location of the Bahrain World Trade Center

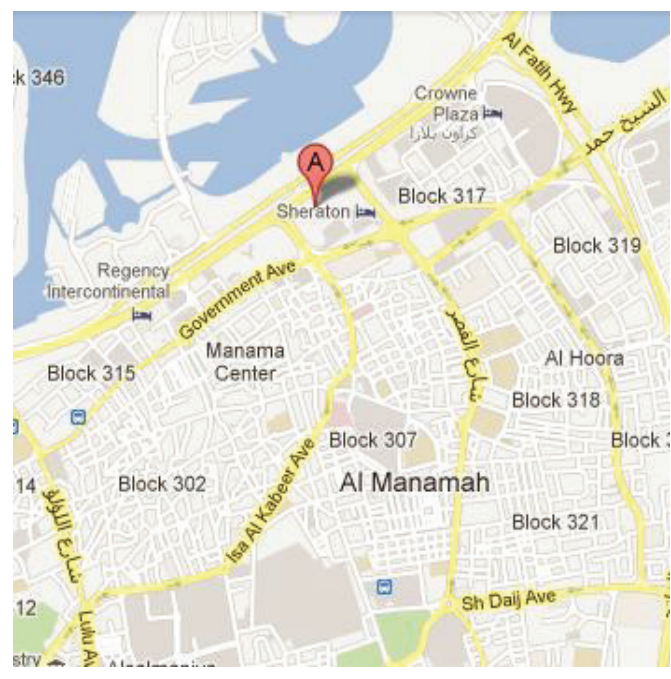

The Bahrain World Trade Center (BWTC) is composed of two towers located in Manama Bahrain. The height of the two towers is approximately 240meter-high $(787 \mathrm{ft}$.) each containing fifty floors. The towers were designed and built in 2008 by the multi-national architectural firm, Atkins. It is regarded as the first skyscraper in the world to integrate wind turbines into its structural design. The wind turbines were developed, built and installed by Danish company Norwin A/S. The Bahrain World Trade Center (BWTC) is built close to the King Faisal Highway, near popular landmarks such as the towers of Bahrain Financial Harbor 
(BFH), National Bahrain Bank (NBB) and Abraj Al-Lulu. The Bahrain World Trade Center is the second tallest building in Bahrain after the twin towers of the Bahrain Financial Harbor (BFH). The twin towers of BWTC are linked with three bridges, each is holding a $225 \mathrm{~kW}$ wind turbine, totaling to $675 \mathrm{~kW}$ of wind power capacity. Each turbine is about 29 meters $(95 \mathrm{ft}$.) in diameter. The three turbines are facing the north direction, i.e. the prevailing wind direction in Bahrain is north and north-north west. On the other-hand the sail-shaped twin towers are designed to funnel the wind through the gap to provide accelerated wind passing through the turbines. This was confirmed by wind tunnel tests, which showed that the building create an S shaped flow, insuring that any wind coming within $45^{\circ}$ angle to either side of the central axis will create a wind stream that remains perpendicular to the turbines. This significantly increases their potential to generate electricity ${ }^{5}$. The three 29m-diameter turbine blades on Bahrain's iconic landmark are the first in the world to be integrated on such a scale into a commercial development. According to the studies, the three turbines are expected to provide $11-15 \%$ (11000-13000 megawatt-hours per year), enough to provide light in 300 homes for three years. The successful rotation of the blades involved collaboration between Atkins architects and engineers and turbine specialists Norwin of Denmark. The noise of wind turbines has been reduced significantly. Improved design has drastically reduced the noise of mechanical components so that most audible sound is that of the wind interacting with the rotor blades ${ }^{9}$. Victor T. Barrera ${ }^{10}$, in his article, "Ten of the Greenest Skyscrapers in the World" listed the BWTC the second of the ten greenest skyscrapers in the world, describing them as "Breathtaking design and practical, clean technology are merged to give us the greenest skyscrapers the world has seen". He stated that "clean technology and green design have both resulted in numerous innovations that continue to push the boundaries of energy generation and efficient resource consumption. Today, urbanization and the increasingly dense populations of the world's largest cities are pushing architects to reach for new heights in green skyscraper design. The Chief Architect of Atkins, Shaun Killa, inspired by nautical expression of a sail to the consistent onshore breeze generating electrical energy. The plans of the two towers were adequately design to help funneling the North and North-west wind to increase the wind speed passing through the three wind turbines. The positioning of the three wind turbines and the unique aerodynamic design of the two towers, the prevailing wind, which is generally from the North and North-west, is funneled into the bath of the turbines producing clean energy. According to Atkins engineers, the idea of the turbines was not only to supply power to the building, but to serve as a landmark in the Kingdom of Bahrain, and be a show case to the entire world as the first commercial building where wind turbines directly integrate into the structure producing non-polluting renewable energy. Three anemometers installed on each 
of the bridges are meant to monitor the wind speed. Different readings from the three anemometers are used to establish the extent of turbulence experienced by the blades at any point of time. The wind turbine communicates with the central unit (UCC) and the BMS through fiber optic cables. Also the controller is required with online connectivity enabling programing from remote locations. For safety considerations, the turbines and its support bridges are integrated to the building structure, any failure of its parts and components could be catastrophic. In view of this, extensive modeling involving around 2000 load cases were carried out to validate and theoretically demonstrate that the turbines and the bridges could survive without excessive fatigue. The main objectives was to incorporate the value of substantially harnessing wind energy by direct integration into a building structure. The knowledge and experience gained could then be disseminated to design teams globally. The outline design of the bridge and turbines was prepared by Atkins. Feasibility study carried out together with the project's unique location facing the Arabian Gulf in the direction of prevailing wind, proves technocommercial validity. The architectural detailed design and engineering was then carried out by wind turbine specialist, M/s Ramboll and their partners M/s Norwin with both companies being headquartered in Denmark. 


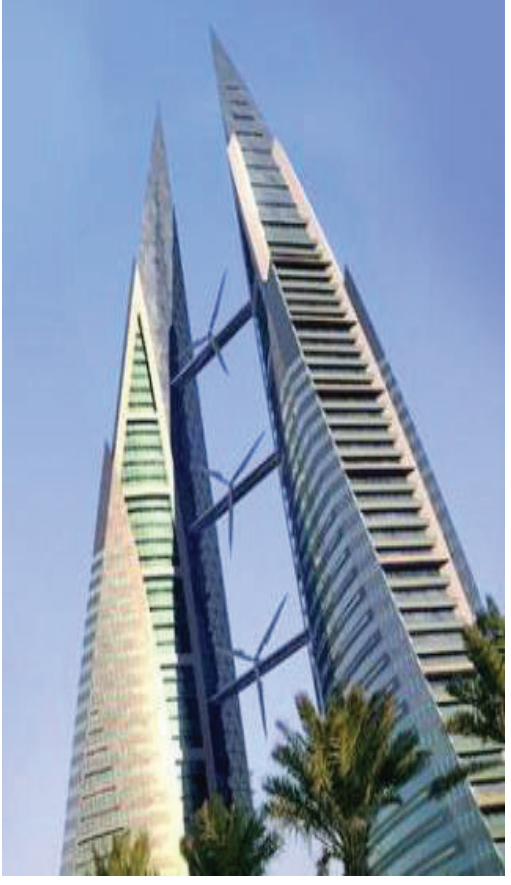

The technical features of the configuration of the wind turbine are as follows ${ }^{2}$ :-

Nominal generating power

$\mathrm{B} /$ lade diameter

Sweep Area

Rotor speed

Generator speed

Survival wind speed

Design life

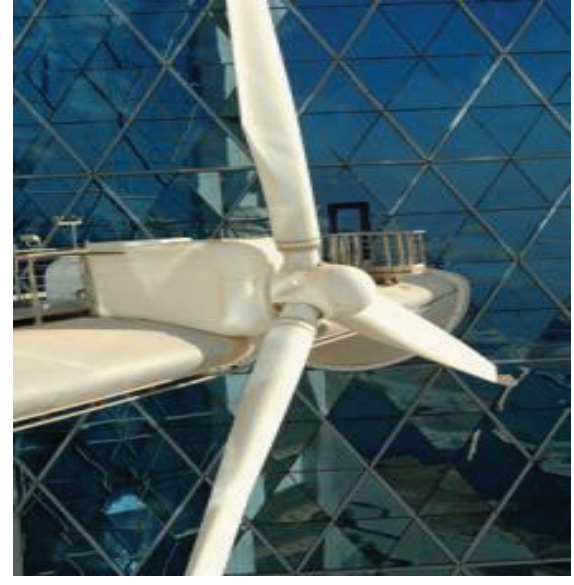

The topmost turbine is on the 35 th floor.

The second one is on the 25th floor.

while the lowest one is on the 16th floor.

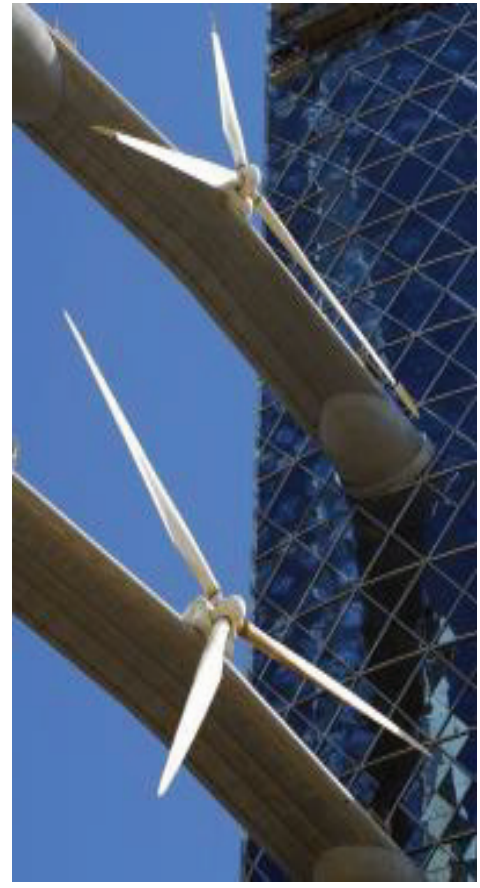

\section{d). Architectural and Technical Design}

The main design criteria's considered for incorporating the wind turbines can be classified as follows ${ }^{3}$ :-

i. Aerodynamic Building Shape:-

ii. The elliptical plan forms and sail-like profiles acts like aero foil, funneling the on-shore breeze between the twin towers creating a positive pressure in the north elevation and a negative pressure in the south elevation, which increases the wind velocity between the two towers. The unique location of the building facing directly opposite the Arabian Gulf insured free availability of the onshore wind.

iii. Operational Limits:-

iv. A number of design parameters have been built into the system, in consideration of the turbines operational efficiency and safety features 
(website 2). The operational wind allowed into the system can be broadly defined as follows:-

- Original wind direction

- Current wind direction

- Cut-in wind speed

+45 deg. to -45 deg.

+60 deg.to -60 deg.

4 meters/sec. Wind speed.

- Wait time for star up from onset of ideal conditions

- Cut-out wind speed

30 minutes.

- Reverse power protection level $\min$.

$21 \mathrm{~meters} / \mathrm{sec}$

$70 \%$ for $5 \mathrm{~min}, 80 \%$ for 30 $90 \%$ for $3 \mathrm{sec}$.

According to the consultant engineer, the achievements can be broadly summarized as follows:-

i. The turbines have been successfully commissioned and have been demonstrated to generate in a manner as intended.

ii. Generated power have been successfully utilized with no detrimental impact on any of the electrical systems.

iii. All safety features have been put to real time test and have been passed.

iv. All automatic controls have been demonstrated to be working in a logical manner in synchronization with the operation of the turbines.

v. Double Glazing (30 $\mathrm{mm}$ in thickness) is used on surfaces exposed to direct solar radiation. This will reduce the surface absorptivity by $90-95 \%$. It allows the light to come in but it cuts the heat. The indoor seems cold even if the outdoor is hot and the air conditioners are off.

vi. The building uses all the glass overall so that to allow the natural lighting into the building and to use less electricity and to save energy and the lights come on when it gets dark or when its night.

vii. Demonstration to local electricity authority EDD have been successfully carried out.

viii. Cost of implementing the scheme have been established to a fraction of the total cost of the project.

Table (1): Wind Turbine Power Production Vs. Diversified Load Connected*

\begin{tabular}{|l|l|l|l|l|l|}
\hline YEAR & $\begin{array}{l}\text { Total } \\
\text { Production } \\
(\mathrm{KWh})(\mathrm{A})\end{array}$ & $\begin{array}{l}\text { Total } \\
\text { Running } \\
\text { Hours }(\mathrm{B})\end{array}$ & YEAR & $\begin{array}{l}\text { Total } \\
\text { Production } \\
(\mathrm{KWh})(\mathrm{A})\end{array}$ & $\begin{array}{l}\text { Total } \\
\text { Running } \\
\text { Hours (B) }\end{array}$ \\
\hline $2008-2009$ & $96,909.69$ & $239: 14: 54$ & 2013 & $91,187.10$ & $3288: 37: 00$ \\
\hline 2010 & $122,209.10$ & $3612: 48: 03$ & 2014 & $80,572.90$ & $2232: 43: 00$ \\
\hline
\end{tabular}




\begin{tabular}{|l|l|l|l|l|l|}
\hline 2011 & $138,699.97$ & $4234: 24: 01$ & 2015 & $109,411.70$ & $3412: 49: 00$ \\
\hline 2012 & $91.686,40$ & $3397: 57: 02$ & 2016 & $28,258.94$ & $974: 27: 00$ \\
\hline
\end{tabular}

Total Production $=758935.80 \mathrm{KWh}$, while the Total Running Hours $=2139: 00: 00$

Table (2): Turbine Production Data from 2008-2016*

\begin{tabular}{|l|l|l|}
\hline Turbine location & $\begin{array}{l}\text { Total Operating Hours } \\
\text { (hrs.) }\end{array}$ & $\begin{array}{l}\text { Total Electricity Produced } \\
\text { During Operation (kwhr.) }\end{array}$ \\
\hline Turbine No. 1 (lowest) & 8735 & $352,054.5$ \\
\hline Turbine No. 2 (middle) & 7434 & $238,358.0$ \\
\hline Turbine No. 3 (top) & 5224 & $168,523.3$ \\
\hline Total Running Hours & 21393 & - \\
\hline Total KWhrs Produced & - & $758,935.80$ \\
\hline
\end{tabular}

Source: Mr. Surajit Biswas; Senior Operation Manager, Bahrain World Trade Center, Oct. 2016.

In the light of the above, and the fact that this design solution was the first of its kind in the world, defines the success of the project. The World Trade Center project offers designers, architects and engineers around the world a huge knowledge on how large wind turbines could be integrated with the building structure as a source of generating renewable energy. The Bahrain World Trade Center project establishes a technological precedent which is set to raise the awareness of environmental design and its importance in the built environment and pave the way for designers and clients to incorporate renewable and energy efficient measures into their future developments to reduce carbon emissions which is causing climate changes. The Bahrain World Trade Center (BWTC) has received international acclaim for its commitment to sustainable development, being awarded LEAF Awards 2006 for "Best Use of Technology within a Large Scheme and recently the Arab Construction World Sustainable Design Award. Wind energy is one of the cleanest, most environmentally friendly energy sources. It emits no greenhouse gases or air pollutants.

\section{e). Concluding Remarks:-}

1. The Bahrain World Trade Center with its magnificent dynamic form is becoming one of the dominant iconic skyscrapers emphasizing the tremendous possibilities of utilizing wind energy in buildings. Its huge 
three wind turbines supported and integrated with the structure of the twin towers will stand there for a long time inspiring the new generation, architects and designers to go for renewable energy technologies.

2. The strong integration of the wind turbines with the structure of the towing towers was a great challenge in itself. There are a number of technological and structural problems which should have been carefully studied and analyzed through rigorous wind tunnel experiments. Of course the findings of the simulation experiments, i.e., wind tunnel experiments will not reflect the exact performance of a full scale building, since such experiments are based on a number of assumptions. Therefore the BWTC could be taken as a full scale model for the utilization of wind energy needed by skyscrapers.

3. The overall design process for designing, constructing and running the project is a real demonstration of how architects, engineers from different specializations and scientists could join together as one team to produce a magnificent building project.

4. The dynamic twin towers and their architectural building form, with its three huge wind turbines pointing toward the outer space gives the feeling that the building is about to take-off like a rocket.

\section{References:}

1. http://www.nortonrosefulbright.com/knowledge/publications/33679/renewable-energyin-bahrain.

2. https://google.com.bh/webhp?source=search_appHp=epa;US Environmental Protection.

3. https://en.wikipedia.org/wiki/Reneable_energy.

4. http://energyinformative.org/wind-energy-pros-and-cons/, Mathias Aarre Maehlum.

5. Bahrain World Trade Center Bahrain” Design Build-network, 2007.

6. "NREL" Dynamic Maps, GIS Data, and Analysis Tools-Wind Maps". Nrel.gov.201309-03. Retrieved 2013-11-06.

7. https://www.buildinggreen.com/feature/folly-build-integrated-wind.

8. www.ewea.org/wind-energy-basis/faq/Wind Energy frequently asked questions (FAQ).

9. Justin Thomas (March 2007), "World's First Building Integrated Wind Turbines", Renewable Energy.

10. http://www.energytrendsinsider.com/2009/05/12/ten-of-the-greenest-skyscrapers-in-theworld/ 